\title{
THE ANTITROCHANTER OF BIRDS: FORM AND FUNCTION IN BALANCE
}

\author{
Fritz Hertel ${ }^{1,3}$ and Kenneth E. Campbell, Jr. ${ }^{2}$ \\ ${ }^{1}$ Department of Biology, California State University, 18111 Nordhoff Street, Northridge, California 91330, USA; and \\ ${ }^{2}$ Section of Ornithology, Natural History Museum of Los Angeles County, 900 Exposition Boulevard, Los Angeles, \\ California 90007, USA
}

Abstract. - The antitrochanter is a uniquely avian osteological feature of the pelvis that is located lateral to the postero-dorsal rim of the acetabulum. This feature makes the avian hip joint unique among all vertebrates, living and fossil, in that a significant portion of the femoral-pelvic articulation is located outside of the acetabulum. This additional acetabular articulation occurs between the neck of the femur and the antitrochanter, and operates as a hinge joint or ginglymus. It is complementary to the articulation of the head of the femur with the acetabulum, which is a pivot joint or trochoides. The size, location, and spatial orientation of the antitrochanter were determined for 77 species of birds representing a variety of hindlimb functions (e.g., highly cursorial, vertical clinging, foot-propelled diving) and spanning a wide range of body sizes (swifts to rheas). The area of the antitrochanter is a good predictor of body mass in birds; its position and orientation are reasonably consistent within hindlimb morphofunctional groups, but not among all birds. The antitrochanter serves as a brace to prevent abduction of the hindlimb and to absorb stresses that would otherwise be placed on the head of the femur during bipedal locomotion. The drum-in-trough-like form of the antitrochanter-femur articulation tends to assist in the transfer of long-axis rotational movements of the femur to the pelvis. The avian antitrochanter is a derived feature of birds that evolved as an aid in maintaining balance during bipedal terrestrial locomotion. Received 7 March 2005, accepted 25 June 2006.

Key words: antitrochanter, bipedality, femur, morphology, pelvis, synsacrum.

\section{El Antitrocánter en las Aves: Forma y Función en el Equilibrio}

Resumen.-El antitrocánter es un carácter osteológico único de las aves que se ubica de modo lateral al borde postero-dorsal del acetábulo en la pelvis. Este trabajo explora las posibles funciones del antitrocánter, así como la estructura y función de la unión con la pelvis. La unión pélvica aviar es única entre todos los vertebrados, fósiles y vivientes, por tener una porción significativa de la articulación femoral/ pélvica ubicada fuera del acetábulo. Esta articulación extra acetabular se produce entre el cuello del fémur y el antitrocánter y opera como un plano de rotación (bisagra) o ginglimo. Además, es complementaria a la articulación de la cabeza del fémur con el acetábulo, que es una unión pivotante o trocoides. El tamaño, la ubicación y la orientación espacial del antitrocánter fue determinado en 77 especies de aves que representan una variedad de funciones de las extremidades posteriores (e.g. altamente cursorial, trepador vertical, nado propulsado por las patas) y abarcan un amplio rango de tamaños corporales (desde vencejos hasta ñandúes). El área del antitrocanter predice adecuadamente el tamaño corporal en las aves, y su posición

\footnotetext{
${ }^{3}$ E-mail: fritz.hertel@csun.edu
} 
y orientación concuerda razonablemente con los grupos morfo-funcionales (según como usan las patas posteriores), pero no entre todas las aves. El antitrocánter sirve como apoyo (traba) para prevenir la abducción de la pata y para absorber presiones que de otra forma se aplicarían a la cabeza del fémur durante la locomoción bípeda. La forma como tambor en canal de la articulación antitrocánter/fémur ayuda en la transferencia de movimientos rotacionales de eje largo, del fémur a la pelvis. El antitrocánter es un carácter derivado de las aves que evolucionó como ayuda para mantener el balance corporal en la locomoción bípeda terrestre.

The Antitrochanter, a unique feature of the modern avian pelvis, is seen in no other vertebrate group, living or fossil. Our data demonstrate that the variable position and orientation of the antitrochanter in relation to the acetabulum is correlated with hindlimb function in birds. We conclude that the antitrochanter serves as a brace to prevent abduction of the hindlimb and to help absorb stresses that would otherwise be placed on the head of the femur during bipedal locomotion. Further, we propose that the form of the antitrochanter-femur articulation assists in the transfer of long-axis rotational movements of the femur to the pelvis.

To our knowledge, the first mention of the avian antitrochanter in the literature was that of Milne-Edwards (1867-1868:41), who referred to it as the "Facette sus-cotyloïdienne," or "supraacetabular facet" (our translation), based on its position in relation to the acetabulum. Owen (1874a:125) used the term "postacetabular facet" in reference to the antitrochanter. The English term "antitrochanteric process" was perhaps first used by Mivart (1874:431), and the term "antitrochanter" has appeared in the literature regularly since then. It is possible that Mivart, in using the term "antitrochanteric process," was following the lead of Owen (1874b: 379), who referred to the facies articularis antitrochanterica (FAAN) of the neck of the femur as the "trochanterian articular surface."

Technically, however, the term "antitrochanter" is a misnomer, because this feature is not in opposition to the trochanter of the femur, as was noted by Milne-Edwards (1867-1868). In fact, in only rare cases does the lateral end of the avian antitrochanter have even minimal contact with the trochanter, which is defined as the "elevated, expanded part of the femur continuous with its neck" (Baumel and Witmer 1993:108). We interpret "elevated" to mean extension proximad, whereas "expanded" refers to extension anteriad. Owen (1874b) used the term "epitrochanterian ridge" for the trochanter as defined by Baumel and Witmer (1993). It should be noted, however, that in some birds (e.g., grebes, cormorants, fulmars) there is no "elevated" part of the proximal end of the femur. In these instances, the collum femoris, or neck, of the femur may extend from the head of the femur to the facies lateralis of the femoral shaft. Admittedly, one may intuitively regard the "neck" of the femur to be a narrow projection of the femoral shaft to which the head is attached, rather than the entire proximal end of the femur. In many birds, however, the head is affixed directly to the shaft of the femur, and there is no "neck" as the word is used in common parlance and as it was used by Owen (1874b). Although Baumel and Witmer (1993) do not define the collum femoris, because they state that it supports the FAAN, it can be inferred that it must represent, in some instances, the entire proximal end of the femur. We follow their usage here, however, rather than create new terminology at this time.

To avoid confusion, it should also be noted that, contra Farlow et al. (2000), the avian antitrochanter is unrelated to the antitrochanter of dinosaurs (see Walker 1977), the probable function of which was to serve as an area of muscle attachment (Romer 1956) as opposed to being an articular surface (see below). Nonetheless, in spite of the recognized complications arising from inappropriate terminology and questionable homologies, we will continue to use the term "antitrochanter" because it is so thoroughly ingrained in the literature. Here, we define and restrict the term "avian antitrochanter" as follows: The avian antitrochanter is an elongated articular facet formed jointly by the ischium and, to an equal or greater extent, the ilium (Fig. 1), which lies adjacent to the acetabulum of the pelvis (Fig. 2), with its proximal end confluent with the rim of the 


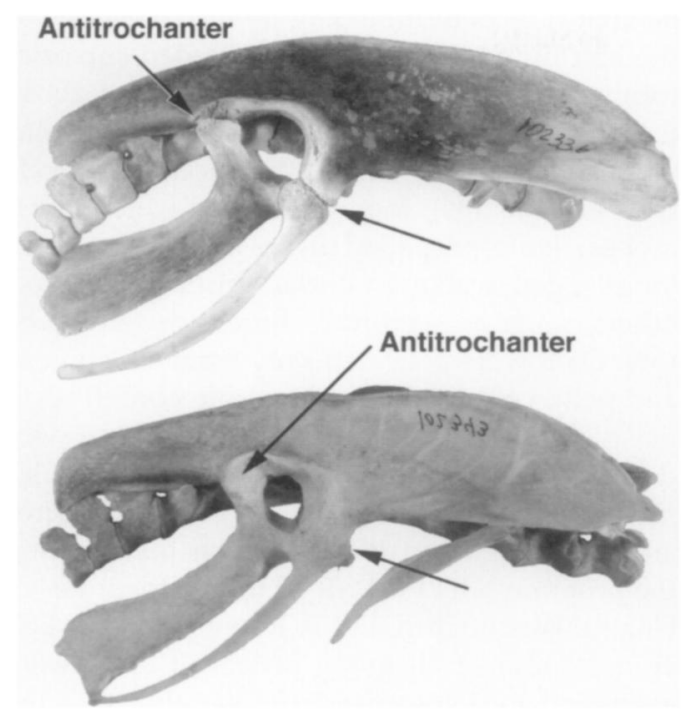

FIG. 1. Maturation of the avian pelvis in the Brown Kiwi (Apteryx australis). (Top) Fledgling pelvis showing the pelvic bones still unfused (arrows). (Bottom) Adult pelvis with complete fusion of all pelvic bones. Note the contribution of the ilium and ischium to the formation of the antitrochanter.

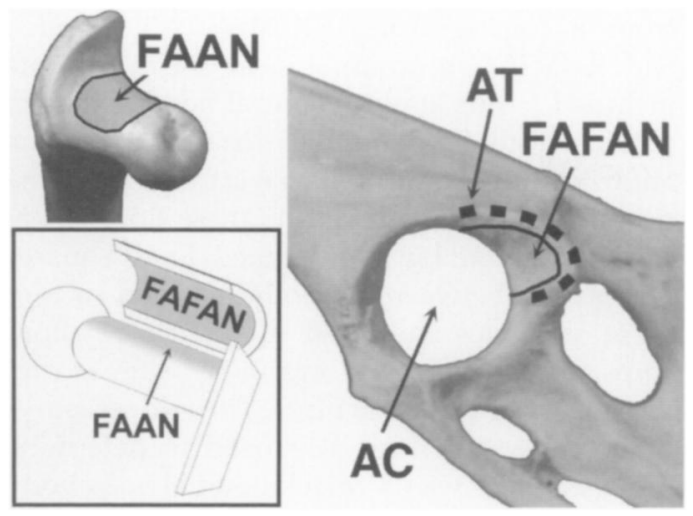

FIG. 2. Diagram showing the articular features of the proximal part of a left femur (left) with the antitrochanter (AT) of the pelvis (right). The concave facies articularis femoralis of the antitrochanter (FAFAN) articulates with the convex facies articularis antitrochanterica (FAAN) of the proximal end of the femur. AC = acetabulum. Inset shows a schematic of the drum-intrough-like nature of the antitrochanter-femur ginglymus. acetabulum and its main body extending postero-laterad from the postero-dorsal quadrant of the rim of the acetabulum. This definition is in agreement with that of Mivart (1874, fig. 74), who illustrated an immature ostrich specimen to document that what he called the "antitrochanter process" was formed half by the ilium and half by the ischium. In contrast, Naples et al. (2002) contended that the antitrochanter is formed solely by the ilium.

The facies articularis femoralis (FAFAN) of the antitrochanter articulates with the FAAN of the neck of the femur. The latter articular facet extends across the neck of the femur from the lateral border of the head to the internal border of the trochanter femoris (Fig. 2), or possibly to the lateral border of the shaft in the absence of an elevated trochanter femoris. On those rare occasions when the antitrochanter appears to come into contact with the trochanter of the femur, it does so when the FAAN extends into the fossa trochanteris of those femora with highly elevated trochanters. In such instances, the distal end of the FAFAN of the antitrochanter can be reflected postero-mediad. The FAFAN is a concave articular facet in transverse cross-section. The depth of the concavity of the antitrochanter varies, generally reflecting the convexity of the FAAN of the femur. The distal end of the antitrochanter is usually open (i.e., it resembles the cut end of an open, shallow trough). Although the antitrochanter is usually a well-defined, linear feature that narrows slightly distad, in some taxa it broadens at its distal end.

The possible functions of the antitrochanter have not been explored in detail in the literature. The only brief discussion concerning this structure is that of Young (1950), who provided an insightful functional explanation for the antitrochanter. He explained that abduction of the leg, or the falling mediad of the bird's body when standing on one leg, is prevented by both the femoral head articulating with the acetabulum and the presence of a second articular surface between the proximal end of the femur and the antitrochanter of the pelvis. In other words, if we have interpreted his work correctly, Young (1950) pictured the antitrochanter as a brace against the proximal end, or neck, of the femur that served to prevent the distal end of the femur from splaying outward, or abducting. Although we agree with this observation, we note that Young (1950) also pointed out that a 
bird balances, in the course of a gait cycle, in the medio-lateral plane by long-axis lateral rotation of the femur brought about by the arrangement of the articular surfaces involved in the knee joint. By his interpretation, the architecture of the knee joints would have the effect of maintaining the center of mass of the bird over the supporting foot by causing the body to roll from side to side in the course of a stride. If this is true, the antitrochanter must also assist in transfering the long-axis lateral rotation of the femur to the pelvis, causing the body to "roll" laterally as the supporting knee is flexed. Our study was designed to explore whether the antitrochanter simply functions as a brace or might also be more complexly involved with the maintenance of balance through a role in transferring forces of long-axis lateral femoral rotation to the pelvis. We also determined whether the spatial orientation of the antitrochanter in relation to the acetabulum of the pelvis was a result of body mass or leg function.

\section{Materials And Methods}

If support is the sole function of the antitrochanter (i.e., a bracing function, as suggested by Young [1950]), a high degree of correlation between the area of the antitrochanter and the mass of a bird would be expected, as well as among the various parameters defining the spatial orientation of the antitrochanter and the mass of the bird. Also, if this were the case, some degree of uniformity among the various parameters defining the spatial orientation of the antitrochanter would also be expected among birds of equal weight classes throughout the class Aves. On the other hand, if the antitrochanter has more of a functional role in locomotion, as well as a role in maintaining balance, the area of the antitrochanter should show a correlation with body mass, but the parameters describing the spatial orientation of the antitrochanter would not be uniform throughout the class Aves. However, these parameters would be expected to be similar within morphofunctional groups of birds.

We measured 100 specimens comprising 77 species from 26 families to determine correlations among the antitrochanter, pelvis, and femur across a variety of avian taxa (Appendix). These species represented a wide range of body sizes (swifts to rheas) and several locomotor behaviors as determined by preferred actions of the hindlimbs. These species included cursorial forms (rheas, roadrunners), climbers or those that suspend themselves to some degree from vertical surfaces (swifts, woodpeckers, woodcreepers, parrots), foot-propelled divers (loons, grebes), wing-propelled divers (auks, penguins), long-legged walkers (storks, ibises, rails), and others, such as seabirds, shorebirds, and raptors. Data were collected only from the femora and pelves of bird skeletons with recorded body mass. Linear measurements were made with digital calipers (accurate to $0.01 \mathrm{~mm}$ ); angular measurements were taken with a protractor and from digitized photos of the bones using the program NIH IMAGE (National Institutes of Health, Washington, D.C.). Representative skeletons of almost all living orders of birds were examined to determine gross variability in the form of the avian antitrochanter and acetabulum. All specimens are housed at the Natural History Museum of Los Angeles County, Section of Ornithology (LACM), or at the Donald Dickey Collections at the University of California, Los Angeles (UCLA). All anatomical terminology used in the descriptions is from Baumel and Witmer (1993).

The area of each antitrochanter was digitized from a tracing using SIGMASCAN (Jandel, San Rafael, California). Linear measurements included femur length, femoral head diameter, pelvic width between the distal ends of the antitrochanters, and pelvic width between the dorsal rims of the acetabula; these linear measurements were log-transformed. Least-squares regressions between log body mass on each of these variables indicated allometric relationships for each variable and their value as predictors of body mass in birds. The two measures of pelvic width were also used to determine whether there was a correlation between body width and femoral splay. That is, do the femora of broad-bodied birds splay more to avoid contacting the abdomen and thorax than those of narrow-bodied birds?

Two angular measurements of the pelvis and one of the femur were taken. First, the antitrochanter angle describes the position of the long axis of the antitrochanter in relation to the vertebral column, in lateral view. To determine this angle, we measured the intersection of an imaginary line drawn through the long axis of the antitrochanter and extended to cross the 
midpoint of the acetabulum, and a second line drawn through the midline of the spinal canal of the vertebrae of the synsacrum (Fig. 3A). Second, the femoral splay angle describes the general degree to which the femur is abducted from the midline of the synsacrum. This angle was determined by measuring the intersection of a line drawn along the long axis of the femur and another through the center of the synsacrum, in dorsal view (Fig. 3B), with the femur held horizontal and in articulation with the antitrochanter. Because the antitrochanter articulates with the neck of the femur, its orientation in the horizontal plane reflects the normal femoral splay in the posture of the bird, or how far from the midline of the bird the distal end of the femur lies. We recognize that curvature of the proximal shaft of the femur, in anterior view, varies among different groups of birds. Also, the long axis of the FAAN of the femur is not always at a right angle to the long axis of the femur, in anterior view. Nonetheless, these two types of variation are limited, and they do not significantly affect the measured degree of splay as defined. The antitrochanter angle and the femoral splay angle should be fairly constant among all birds, unless the spatial orientation of the antitrochanter is critical to the action of a bird's hindlimb, in which case considerable variation throughout the class Aves would be expected.

The femoral angular measurement taken was the fibular angle. This angle is a measure of the posterior projection of the trochlea fibularis (fibular condyle) of the femur in relation to that of the condylus lateralis (lateral condyle) of the femur, which is one reflection of the differences in form of these two articular surfaces. The angle is defined by the intersection of a vertical line drawn through the crest of the lateral condyle of the femur, in distal view, and another from the most posterior point of the lateral condyle to the posterior edge of the lateral crest of the fibular condyle (Fig. 3C). If, as suggested by Young (1950), the arrangement of the joint surfaces of the knee imparts a long-axis, lateral rotation to the femur in the course of a stride, this angle may indicate the degree of that femoral rotation. That is, we tested the prediction that the disparity between the articular surfaces of the trochlea fibularis and the condylus lateralis of the femur, as reflected in the fibular angle, is an indicator of long-axis lateral rotation of the femur when the knee is flexed.

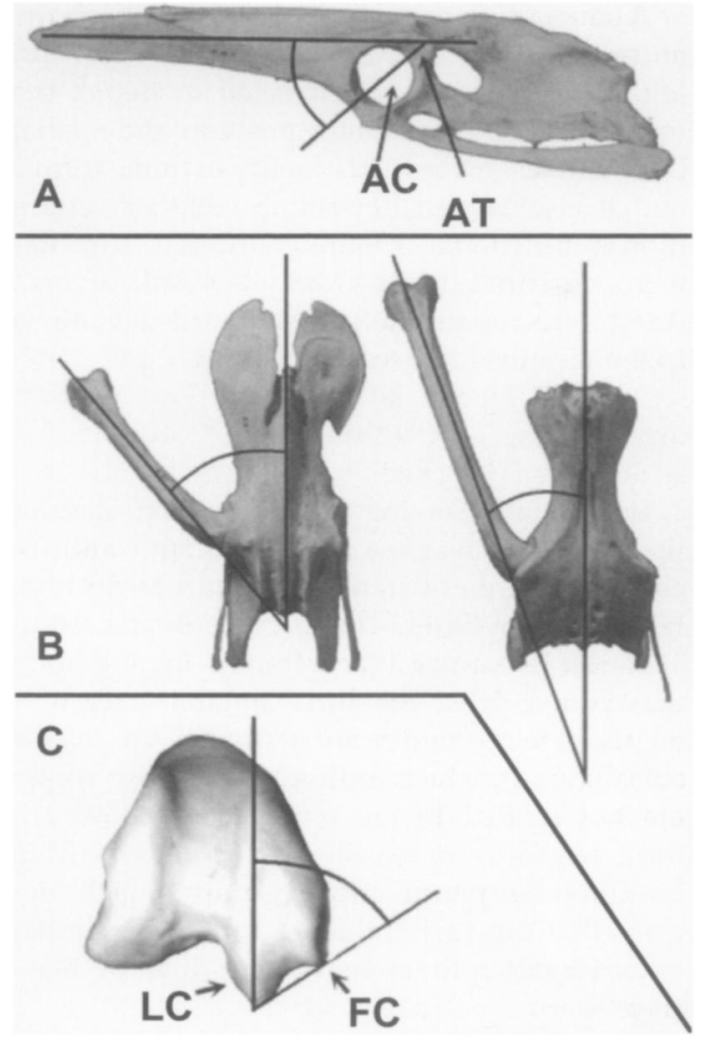

Fig. 3. (A) Left lateral view of the pelvis showing the antitrochanter angle that describes the position of the antitrochanter (AT) in relation to the rest of the pelvis in the vertical plane; this angle was defined by a line drawn through the long axis of the antitrochanter and the midpoint of the acetabulum (AC), and a second line drawn through the spinal canal of the synsacrum. (B) Dorsal view of the synsacrum of an Adélie Penguin (left) and a Great Blue Heron (right); the femoral splay angle is that angle at the intersection of a line drawn along the long axis of the femur and a line through the vertebral column. The Adélie Penguin holds its femur at a greater angle than the Great Blue Heron $\left(40^{\circ}\right.$ vs. $20^{\circ}$, respectively), despite its narrower pelvic width. (C) Distal view of the distal end of a left femur showing the fibular angle, which is defined as the disparity between the posterior projection of the fibular condyle (FC) and the lateral condyle (LC). The greater the angle, the less the disparity. 
A three-dimensional representation of the antitrochanter angle, femoral splay angle, and log body mass was constructed to depict the variation in antitrochanter position and spatial orientation. This helped identify extreme forms, and it also helped determine whether certain morphofunctional groups clustered together (e.g., cursorial birds, foot-propelled divers). Axes were represented as standard deviations of the mean value for each variable.

\section{Results}

Regressions for log body mass on each of the femoral linear measurements and antitrochanter area were significant, with fairly high regression coefficients $\left(0.79<r^{2}<0.90, P<0.001\right.$; Table 1). By contrast, regressions for log body mass on each of the three angular measurements were not significant $\left(0.007<r^{2}<0.030, P>\right.$ 0.08 ; Table 1), which indicates that these angles are not related to the bird's mass. However, these angles were reasonably consistent within hindlimb morphofunctional groups, which suggests that they are influenced more by similar body form, leg function, or both, than by mass (Figs. 4-6).

Some general trends can be observed from the angular measurements. The antitrochanter angle was greatest for foot-propelled divers
TABLE 1. Regression statistics for log body mass on eight variables; linear measurements were logtransformed; NS = not significant $(P>0.08)$.

\begin{tabular}{lcc}
\hline \hline Variable & $r^{2}$ & $P$ \\
\hline Femoral head diameter & 0.90 & $<0.001$ \\
Antitrochanter area & 0.81 & $<0.001$ \\
Femur length & 0.79 & $<0.001$ \\
Intertrochanteric width & 0.64 & $<0.001$ \\
Interacetabular width & 0.57 & $<0.001$ \\
Antitrochanter angle & 0.03 & NS \\
Femoral splay angle & 0.01 & NS \\
Fibular condyle angle & 0.03 & NS \\
\hline
\end{tabular}

(loons and grebes), followed by those species that tend to climb or suspend themselves from vertical surfaces (woodcreepers, swifts, parrots, woodpeckers; Fig. 4). The femoral splay angle, or the angle between the articulated femur and the midline of the synsacrum in dorsal view (Fig. 3B), is highly variable among birds. For example, an Adélie Penguin (Pygoscelis adeliae) holds its legs at a much greater angle to the midline of the body than a Great Blue Heron (Ardea herodias) $\left(40^{\circ}\right.$ vs. $20^{\circ}$, respectively; Fig. 3B), though both are similar in body mass. The femoral splay angle was greatest for loons and grebes (Fig. 5). The fibular condyle angle was greatest in albatrosses, closely followed by loons and grebes. It was lowest for more

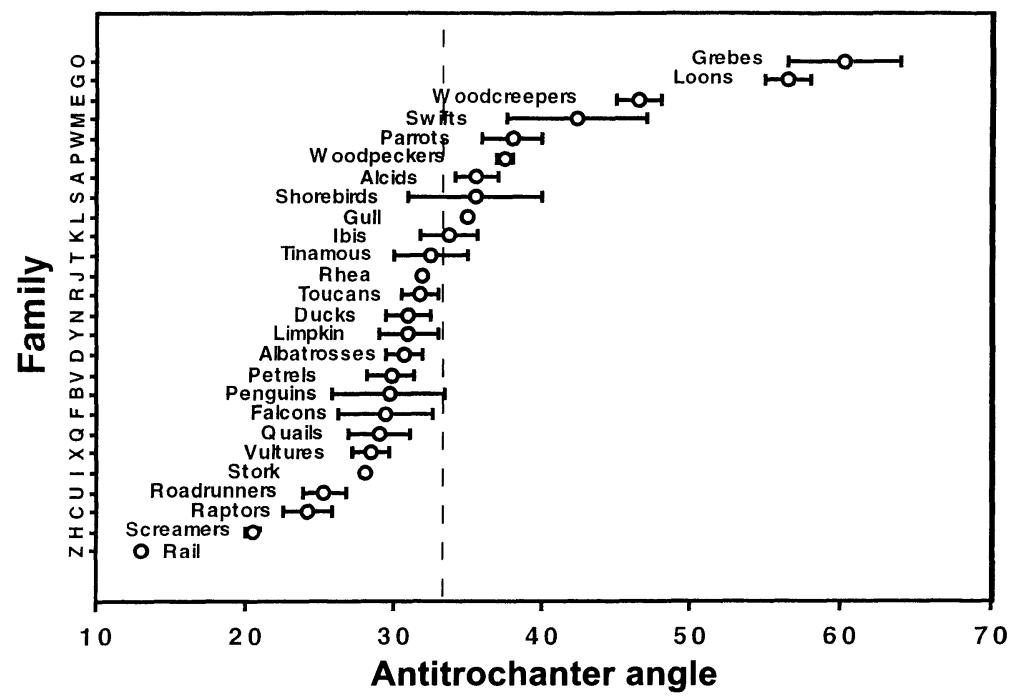

FIG. 4. Antitrochanter angle with standard errors for a variety of birds; dashed line indicates the mean value for all specimens; family codes on vertical axis are given in the Appendix. 


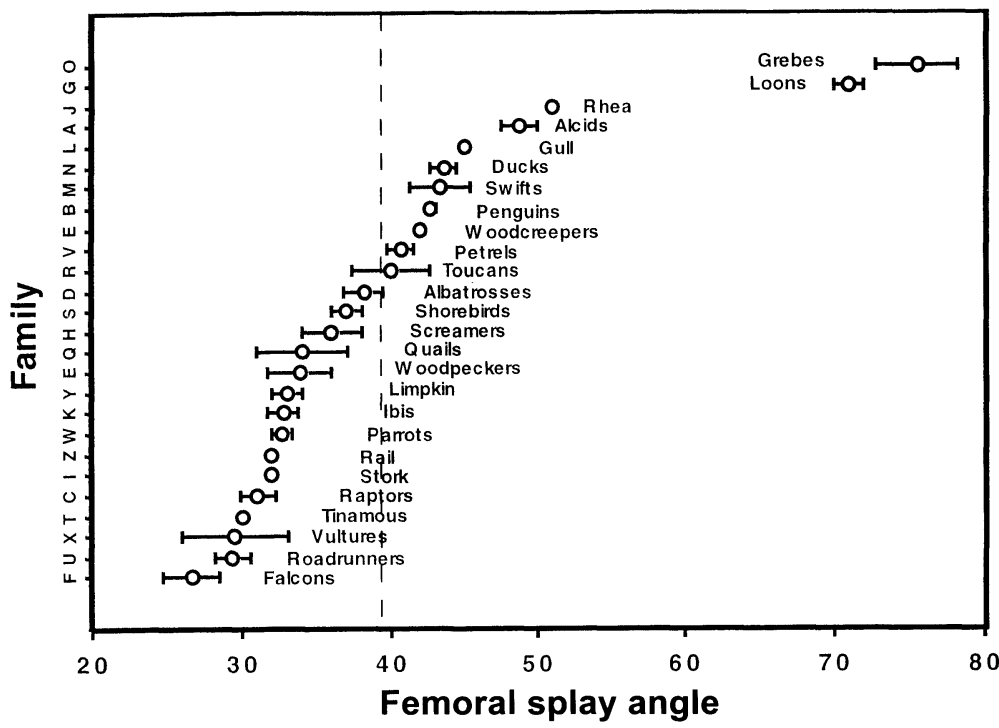

Fig. 5. Femoral splay angle with standard errors for a variety of birds; dashed line indicates the mean value for all specimens; family codes on vertical axis are given in the Appendix.

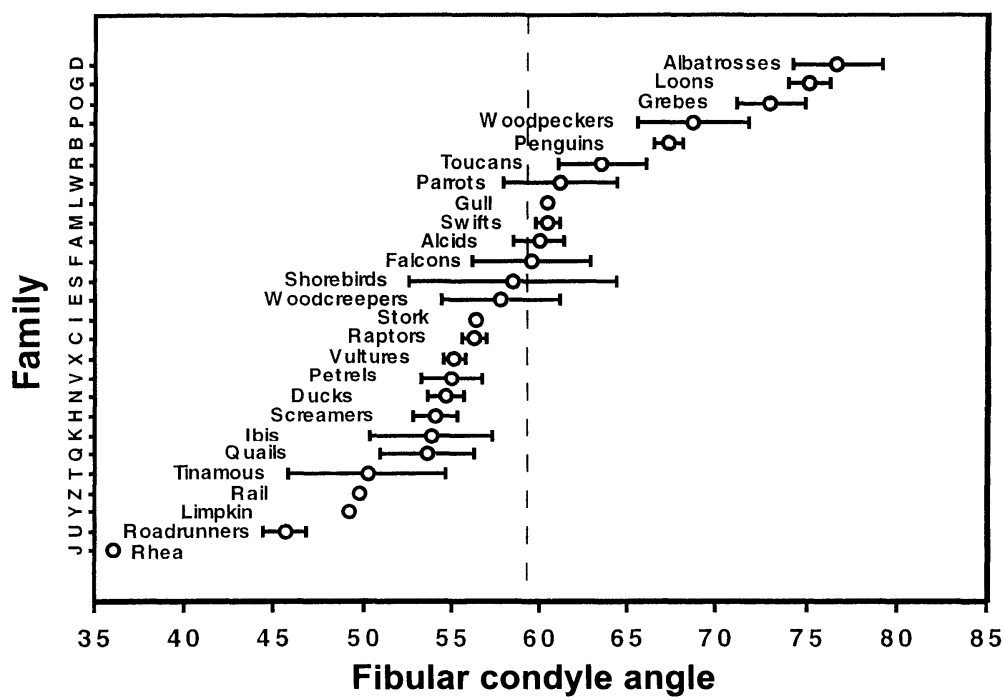

FIG. 6. Fibular condyle angle with standard errors for a variety of birds; dashed line indicates the mean value for all specimens; family codes on vertical axis are given in the Appendix.

ambulatory species, such as rheas, roadrunners, rails, and tinamous (Fig. 6).

Combining the femoral splay angle and the antitrochanter angle with body mass gives a variety of positions in morphospace occupied by the antitrochanter (Fig. 7), which in turn determines the overall position at which the femur is held to the body. As can be seen in Figure 7, there is no discernible mass-related spatial orientation for birds as a whole. The most aberrant forms are found in the loons and grebes ( $\mathrm{G}$ and $\mathrm{O}$ in Fig. 7). 


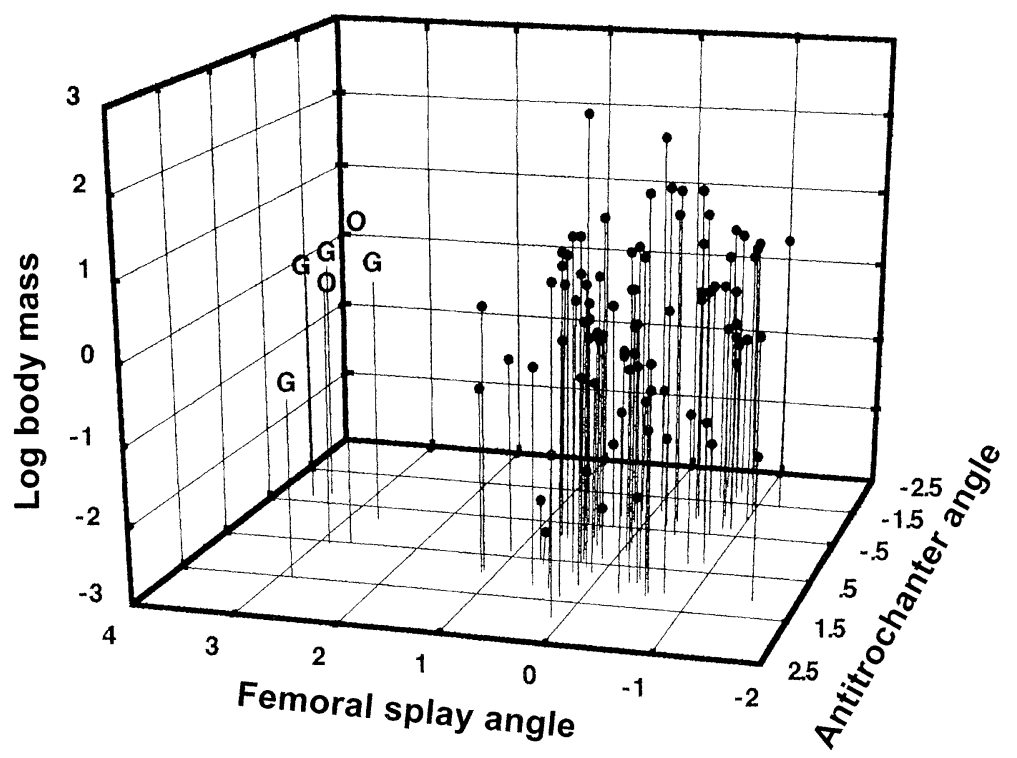

FIG. 7. Three-dimensional graph of the variation in position (antitrochanter angle) and orientation (femoral splay angle) of the antitrochanter with log body mass in a variety of birds. Axes are represented as standard deviations of the mean value for each variable. Loons $(G)$ and grebes $(O)$, both foot-propelled divers, have the most distinctive values.

Intertrochanteric and interacetabular widths were not as strongly correlated with body mass as were the other linear measurements, though the correlations were significant. There was a significant negative correlation between each of these measures of pelvic width and femoral splay angle (Pearson's coefficient $r=-0.40, P<$ $0.001)$. However, when the loons and grebes were excluded, the correlations were not significant (Pearson's coefficient $r=-0.28, P>0.06$ ). This suggests that femoral splay angle is somewhat independent of pelvic width, as these two characters were measured.

There was a significant positive correlation between the femoral splay and fibular condyle angles (Pearson's coefficient $r=0.40, P<0.001$ ). These results indicate that the more the femur is abducted from the midline of the body (i.e., greater splay), the greater is the fibular angle (i.e., less disparity between the posterior extension of the condylus lateralis and trochlea fibularis). This may pose a problem with Young's (1950) hypothesis regarding long-axis femoral rotation, as discussed below. Because neither of these angles correlates well with mass, it must be assumed that their correlation is a result of leg function.

\section{Discussion}

Femoral linear measurements and antitrochanter area are strongly correlated with body mass. These results were expected and complement those of other studies of birds, which have shown a strong correlation between femur length and body mass (Hertel 1992) and least circumference of the femur and body mass (Campbell and Tonni 1983, Campbell and Marcus 1992). The strongest parameters to correlate with body mass in this study were femoral head diameter and antitrochanter area (Table 1), which is not surprising, given that these are measures of regions where loads are transferred from the pelvis to the femur. Thus, portions of the pelvis and femur, including the antitrochanter and the femoral head, can be good predictors of body mass in birds. These bones are often preserved as fragmentary fossils and, therefore, can serve as important paleoecological indicators of the taxa in question.

The results of the pelvic width comparisons with body mass, which were not as strongly correlated, suggest that pelvic width may be a consequence of hindlimb function. For example, Raikow (1970) found that a decrease 
in interacetabular width among dabbling ducks was associated with streamlining the body for foot propulsion. Similarly, pelvic width does not seem to influence femoral splay angle, but this may be because pelvic width is not strongly correlated with body mass. That is, great width through the acetabula does not necessarily mean a wide abdomen or thorax. In the aforementioned example of the Adélie Penguin and Great Blue Heron, the pelvis of the Great Blue Heron through the acetabula is much wider (Fig. 3B), but the femoral splay angle is much larger in the Adélie Penguin. Although this may at first seem paradoxical, it can be observed that the anterior iliac portion of the pelvis is much broader in the Adélie Penguin than in the Great Blue Heron. In this case, it may be that the width of the anterior portion of the pelvis is more critical for determining femoral splay than the width through the acetabula.

Although the three angular measurements did not correlate with body mass, they were reasonably consistent within families and hindlimb morphofunctional groups, which suggests that leg function is the critical determining factor for these angles. The data show that whereas many groups have a relatively low antitrochanter angle (i.e., a femur more parallel to the vertebral column in the vertical plane), some species have large antitrochanter angles (woodcreepers, swifts, parrots, woodpeckers; Fig. 4), and a few others have very large antitrochanter angles (e.g., loons and grebes). An even greater variation was observed in the distribution of the femoral splay angle among the families examined (Fig. 5), which points out the wide variation in the stance of birds. Perhaps the most extreme combination of large antitrochanter angle and large femoral splay angle ever achieved in birds is that seen in the Cretaceous diver Hesperornis, a combination that is closely approximated by that observed in living loons and grebes. The femur of Hesperornis was held in an almost horizontal position, projecting almost directly laterad from the body (Fig. 8). In this instance, the femur is abducted about as much as possible without beginning to adduct over the top of the bird, which suggests that the antitrochanter was acting in some capacity other than just to limit abduction.

Our selected sample of taxa measured was intended to provide as great a variety of forms and body sizes as possible, rather than closely

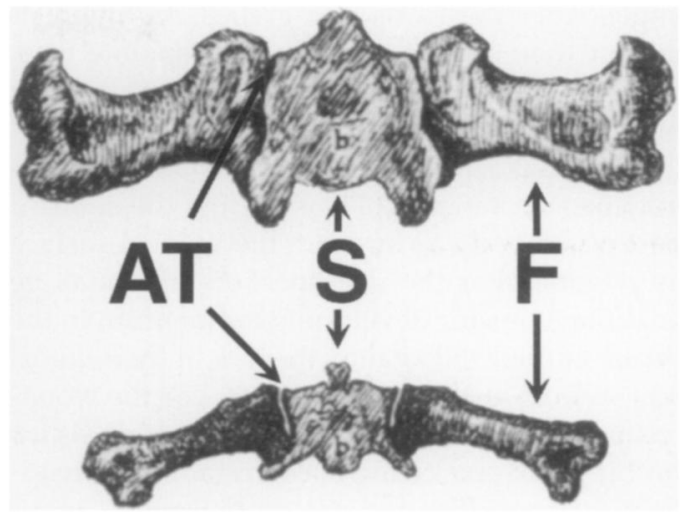

FIG. 8. Anterior view of the synsacrum (S) and femur (F) of Hesperornis (top) and a grebe (bottom) showing the position of the antitrochanter (AT) and the greatly splayed orientation of the femur (modified from Heilmann 1926).

examine any specific morphofunctional group in detail. Our data are also limited to too few individuals within any given taxonomic group to allow acceptable statistical comparisons among them. However, our data show that variables in birds from distantly related families with similar locomotory modes are similar. The best examples are the loons and grebes. The few specimens of diving ducks had slightly higher values for the antitrochanter angle than dabbling ducks in the same direction as loons and grebes. Woodpeckers and toucans are in the same order (Piciformes), yet the antitrochanter angle for woodpeckers was more similar to that of parrots and woodcreepers, both of which are in different orders. Greater samples are required before making solidly based functional interpretations of these types of data, but some observations may be warranted, if only to suggest future lines of inquiry. For example, in the case of the foot-propelled divers, the combination of a high antitrochanter angle and a high femoral splay angle serves to position the feet farther posteriorly and farther apart. In these taxa, the pelves tend to be very narrow, a reflection of the stream-lining of the body for effective diving and pursuit movement underwater, and the broad spacing and posterior positioning of the feet are effective adaptations for maximizing underwater propulsion.

The large antitrochanter angles observed in the woodcreepers, swifts, parrots, and woodpeckers, which have the highest antitrochanter 
angles after the loons and grebes, are interesting for their occurrence in such disparate taxa. What these taxa share is their habit of climbing or clinging to vertical surfaces. We suggest that in these taxa, the high antitrochanter angles may be adaptations for positioning the anterior part of the body as far from the vertical surface as possible. For the woodpeckers, this may be advantageous for developing momentum in the thrust of their bill against the tree in their vigorous style of searching for insects. For the woodcreepers, many of which have very long bills for probing into cracks and bark, the ability to readily position the head at a distance from the vertical surface is also an advantage. In both groups, increasing the distance between the head and prey may increase visual acuity. For parrots, which use their heads frequently in climbing, a large antitrochanter angle would offer a greater reach and a greater access to food resources. We note that the parrots and woodpeckers, which are zygodactylous, have much smaller femoral splay angles than the woodcreepers and swifts. This suggests that zygodactyly may confer some limits on leg-hip joint morphology, but this is not necessarily linked with scansorial activities (Bock and Miller 1959). An unexpected result for an antitrochanter angle was the condition observed in penguins, in which this angle falls just below the mean angle for all bird groups (Fig. 4). This result is surprising because when penguins are on land, their vertebral column, and thus their pelves, are held in a near-vertical position. However, in illustrations and mounted skeletons of specimens in museums (Feduccia 1999), the femora of penguins are often shown held in a nearly horizontal position. This is clearly an incorrect pose, because the articular facet (FAAN) of the femur would not be in contact with any portion of the antitrochanter. In fact, the femur in standing penguins is held at a very steep angle to the horizontal. This severely limits the degree of flexion-extension of the knee joint in this group of birds. We propose that this unusual orientation of the hindlimb bones contributes to the high energetic cost of terrestrial locomotion in penguins (Pinshow et al. 1977).

Balance in bipeds. - In bipedal animals at rest in a standing position, the animals' center of mass must lie directly over both feet to maintain stability at a minimal energetic cost (Storer 1971). During locomotion, when one leg is elevated, the biped's entire mass is supported by the single planted foot, and its center of mass must be placed over that foot to maintain balance and avoid falling to one side. In bipedal animals such as the Mesozoic theropod dinosaurs, with their long, muscular tails to counter the weight of the anterior end of the animal, the whole body could be balanced like a teeter-totter on the heads of the femora (Tarsitano 1983). This support system was aided by the fact that the femora of these dinosaurs were oriented fairly vertically (Colbert 1989), and flexion-extension was in a parasagittal plane and rooted in the femoral-pelvic articulation. Lateral tail movements could also be used to shift the body's center of mass, thereby assisting balance when the animal stood on one foot. This type of support system may also have been present in the oldest known bird, the long-tailed Archaeopteryx, though the evidence is not yet clear. In modern birds, however, there is no long, bony, muscular tail, and there is a large mass of anteriorly positioned pectoral musculature that places the body's center of mass well forward of the hip joint. Thus, it can be assumed that in the course of avian evolution it was necessary, for the maintenance of balance, for the distal end of the femur to move forward in relation to the hip joint to keep the feet under the center of mass. The end result of this evolutionary sequence is a femur in modern birds that is positioned at a low angle to the horizontal (Campbell and Marcus 1992, Gatesy 1999).

One consequence of moving the femur to a more horizontal position is that the distal end had to abduct, or splay away from the midline of the bird, to avoid contact with the abdominal cavity and thorax. However, abduction of the femur gives a wider stance that creates new support problems at the hip and knee joints because it results in long-axis torquing forces on the femur that are greater than if it was held more vertically. This is because, rather than the femur providing support from directly under the pelvis, the support must be cantilevered to the hip joint from a knee joint that is located anterior and lateral to the hip joint (Campbell and Marcus 1992, Carrano 1998). In particular, as a consequence of the femur moving to a more horizontal and a more splayed position, the force vectors placed on the head of the femur are different from those experienced when the femur is held vertically under the body. That 
the area of the antitrochanter correlates well with the mass of a bird is a strong indication that it is serving a support role, and we propose that this osteological feature of birds evolved as they lost the long, bony, muscular tails of their ancestors and their center of mass moved anteriad. We suggest that a primary function of this new, additional acetabular articular facet was to relieve stress on the head of the femur resulting from increased abduction of the femora by providing a secondary articular facet with the neck of the femur that absorbs some of this stress. This interpretation is further supported by the different orientations of the antitrochanter in different modes of nonflying locomotion.

In addition, as a consequence of the wider stance resulting from the femur moving to a more horizontal and more splayed position, significant movement laterad of the center of mass is required to maintain balance during locomotion. This is because, in bipeds with a wide stance, when one foot leaves the ground, the body's center of mass would be farther from a position directly over the remaining foot than would be the case in bipeds with a narrow stance. Somehow, the center of mass must be moved to a position over the stance foot, or the animal would collapse to the unsupported side. Young (1950) proposed that birds solved this problem through the evolution of a system whereby the arrangement of the articular surfaces comprising the knee joint caused a long-axis lateral rotation of the femur when the joint was flexed, though he did not detail how he believed the rotation was brought about. In Young's (1950) hypothesis, lateral femoral rotation helped maintain balance in a bird by rolling the body of the bird laterally over the planted foot while the other foot was in the swing phase of a gait cycle (Fig. 9). If Young's (1950) hypothesis were valid, the wider the stance of a bird the more the bird would need to rotate laterally to bring its center of mass over the supporting knee and the planted foot.

For the present study, we assumed that Young (1950) based his interpretation on the differences in form between the adjacent trochlea fibularis and condylus lateralis of the femur, because the latter is the most variable articular surface of the knee among birds and because its radius of curvature differs from that of the trochlea fibularis. We considered the possibility that long-axis lateral rotation of the femur could be

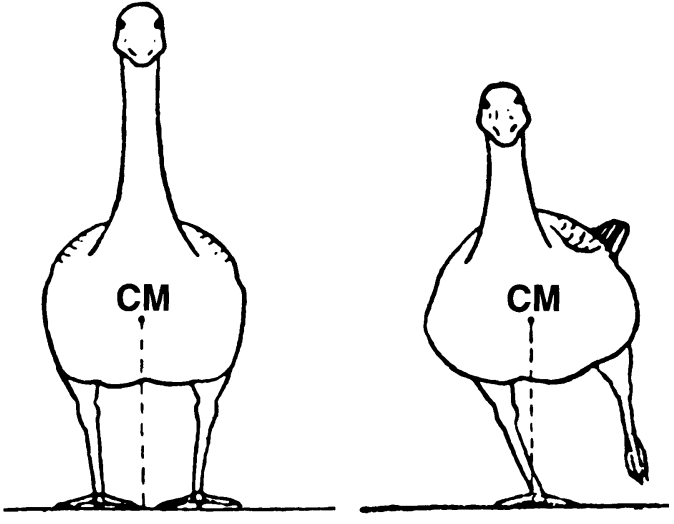

FIG. 9. Standing position (left) and walking position (right) of a bird showing the lateral rotation of the body and, hence, its center of mass (CM), over the contact foot during propulsion caused by long-axis rotation of the femur, as proposed by Young (1950).

reflected in the disparity between the posterior extensions of the articular surfaces of the lateral condyle and the fibular trochlea, in distal view. A complicating factor that must be recognized is that the articular surfaces of the lateral condyle are found on its medial and lateral surfaces, as opposed to the condition for the condylus medialis and trochlea fibularis, where the articular surfaces lie on the posteroventral surface. We tested this interpretation of Young's (1950) hypothesis by measuring what we refer to as the fibular angle (Fig. 3C). If the noted disparity in the posterior extensions of the articular surfaces of the condylus lateralis and trochlea fibularis was the cause of the long-axis, lateral femoral rotation, we expected that the fibular angle should decrease as the splay angle increases. Our data, however, show that just the opposite happens: as the splay angle increases, so too does the fibular angle, which indicates a convergence in shape between the trochlea fibularis and condylus lateralis. We conclude, therefore, that lateral femoral rotation during the stance, or support, phase of a gait cycle in a bird is not caused by the arrangement of the articular surfaces of the condylus lateralis and trochlea fibularis, as measured by the fibular angle.

Nonetheless, birds tend to roll laterally over their planted foot during bipedal locomotion (Gatesy 1999, F. Hertel and K. E. Campbell, Jr. pers. obs.). Thus, another mechanism must 
be the cause of this roll. We agree with Young (1950) in that we believe this mechanism involves long-axis rotation of the femur that originates within the knee joint, and we are addressing this question elsewhere. Regardless of the cause of the roll, we propose that the articulation between the antitrochanter and the neck of the femur, in combination with muscles and ligaments, helps to ensure that the long-axis lateral rotation imparted to the femur from the distal leg is passed on to the pelvis. To understand how the antitrochanter helps transfer lateral rotation of the femur to the pelvis, causing the latter to roll laterally, it is necessary only to picture the antitrochanter as an elongated, shallow trough, which it resembles, at least in part. The elongated neck of the femur fits into the trough, which helps to lock the femur and pelvis together and minimize rotation of the femur on the pelvis (Fig. 2, inset).

We have discussed femoral abduction in terms of the degree of splay of the distal end of the femur from the midline. There is another way for femoral abduction to occur, however, and that is long-axis medial rotation of the femur. As noted above, if a bird lifted one foot without shifting its center of mass over the planted foot, it would fall toward the lifted foot. This would result in abduction of the femur as it undergoes long-axis medial rotation in relation to the pelvis, though there would undoubtedly be an increase in femoral splay as well. If the center of mass is shifted over the planted foot, however, the body is balanced and it will not fall toward the lifted foot, and long-axis medial rotation of the femur will not occur.

Hutchinson and Gatesy (2000) stated that an erect biped cannot balance statically on one leg if the foot is placed lateral to the hip joint. They proposed that in birds the planted foot lies under the midline of the body and that balance is maintained by long-axis medial rotation of the femur brought about by pelvic musculature (i.e., the M. iliotrochantericus caudalis [ITC] and M. iliotrochantericus medius [ITM]) exerting a pull on the femur. They propose that medial rotation of the femur "allows the toes of the planted foot to push laterally against the substrate and prevent pelvic collapse" (Hutchinson and Gatesy 2000:749). The collapse to which they refer is hip adduction. In their model, they do not recognize medial rotation of the femur as leading to hip abduction. Although Hutchinson and Gatesy (2000) suggest that the foot must be under the midline of the body at the level of the hip joint during the stance phase of locomotion, femoral splay makes this physically impossible. Furthermore, femoral splay cannot be compensated for by movements at the knee and ankle joints, because movements at these joints are relatively restricted to the parasagittal plane.

We agree that in birds the foot tends to lie under the midline of the body during the stance phase of a stride, but we contend that the critical element for the maintenance of balance is the position of the center of mass in relation to the foot, not the position of the hip joint in relation to the foot. We note that when a bird is at rest with both feet planted they cannot both be under the center of mass, and because of femoral splay, the center of each foot must be lateral to the hip joints. We propose that at the initiation of a stride, the center of mass is rotated over the stance foot by a combination of pelvic roll and pelvic yaw, both of which are known to occur (Gatesy 1999, F. Hertel and K. E. Campbell, Jr. pers. obs.). The resulting movement is the avian waddle, which is more evident in some birds than in others.

Pertinent to this issue is the fact that published data tend to confirm that in the stance phase the ITC and ITM are in contraction (Jacobson and Hollyday 1982, Gatesy and Dial 1993, Gatesy 1994, Johnston and Bekoff 1996). However, if the pelvis could rotate in relation to the femur, it could be predicted that the contraction of these muscles would result in a lateral roll of the pelvis rather than effect long-axis medial rotation of the femur. The reason for this is that in this situation the femur is locked into the knee joint while the pelvis is suspended, being supported by the proximal end of the stance femur. The contracting pelvic musculature cannot rotate the femur, because the pelvis is not anchored and the femur is. In that we find that the antitrochanter tends to lock the femur and pelvis together, we believe that it is more probable that the ITC and ITM act to prevent adduction by holding the pelvis onto the femur as the center of mass is being moved laterally over the planted foot. In effect, this action is equivalent to preventing lateral rotation of the femur in relation to the pelvis, which is the function of the ITC and ITM proposed by Gatesy (1994). This is not the same as the suggestion by Hutchinson and Gatesy (2000) that contraction of the ITC and ITM creates long-axis medial 
rotation of the femur for the purpose of transferring lateral forces to the toes.

We emphasize that we find long-axis lateral rotation of the femur to be initiated in the knee joint. This rotation is passed on to the pelvis, in part via muscles and ligaments and in part via the antitrochanter-femur ginglymus. The result is the observed lateral roll of the pelvis. In this, we agree with Young (1950). The driving mechanism for this lateral rotation of the femur will be addressed elsewhere.

Evolutionary implications. - The antitrochanter as defined here is a uniquely avian structure. It is also a feature that evolved after the appearance of the earliest birds. An antitrochanter was not present in the Jurassic bird Archaeopteryx (Fig. 10), nor in the early Cretaceous Chinese bird Caudipteryx (Fig. 10), which some authors (Ji et al. 1998) regard as a feathered theropod dinosaur (see discussion of differing viewpoints in Paul 2002). It should be noted that both of these early avian taxa possessed long, bony tails that may have served to assist in maintaining balance. Naples et al. (2002) stated that the early Cretaceous Chinese birds Confusiusornis and Cathayornis have small antitrochanters, and Chiappe et al. (2002) agreed that there might be a small antitrochanter in Confusiusornis. Zhou and Hou (2002), however, state that there is no antitrochanter in Cathayornis. Nonetheless, antitrochanters are present in other enantiornithiform birds (Chiappe and Walker 2002; K. E. Campbell, Jr. pers. obs.)

Despite Romer's (1956) assertion that the antitrochanter of dinosaurs is an area of muscle attachment and Walker's (1977:330) observation that dinosaurs "have no true antitrochanter as is present in the bird," some authors continue to

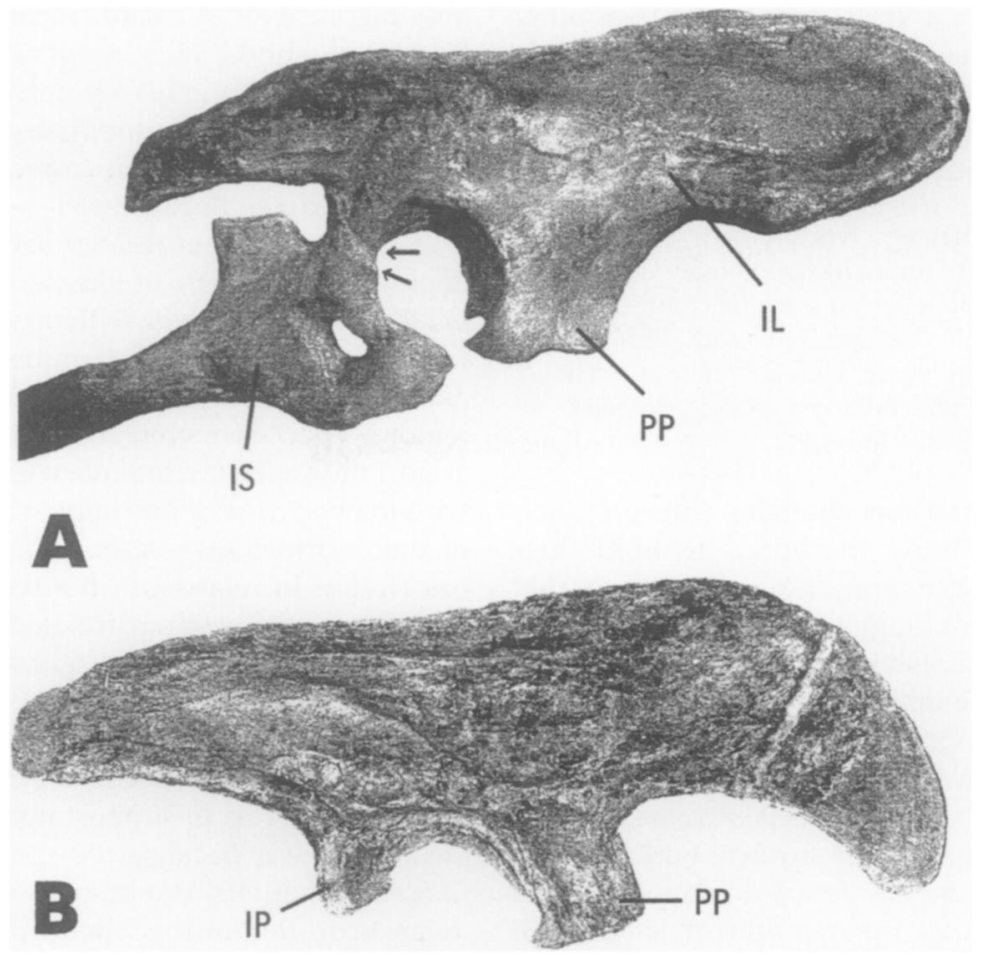

Fig. 10. The ilium and ischium of (A) Archaeopteryx and the ilium of (B) Caudipteryx do not have any structures that could be interpreted as an antitrochanter. In the London specimen of Archaeopteryx (A), there has been displacement of the ischium from the ilium, the amount of displacement being indicated here by the two arrows lying within the acetabulum. The top arrow indicates the ventral edge of the ischiadic peduncle of the ilium, whereas the lower arrow indicates the line along which this edge would attach in life. (IL) ilium, (IP) ischiadic peduncle, (IS) ischium, (PP) pubic peduncle. Ilia not to scale. Anterior to right. 
refer to a structure on some dinosaurian pelves as homologous with the avian antitrochanter. For example, Altangarel et al. (1994) described an antitrochanter on the pelvis of Mononykus, a most unusual theropod dinosaur they claimed to be an early bird, though one of the authors (Chiappe 2001) has since demurred from this suggestion. This structure bore no resemblance to an avian antitrochanter, however, in that it lies in the posteroventral quadrant of the acetabulum, and it is convex in transverse crosssection, as is the proximal end of the femur. This description was reiterated by Chiappe et al. (2002). For the femur to have articulated with this feature as it does with the antitrochanter in a bird, the distal end of the femur would have had to extend dorsad, with its distal end dorsal to the vertebral column, in a sort of "grasshopper" mode. Further, we know of no vertebrate hip joint where two bones articulate via two convex surfaces, and we regard the possibility of such an articulation in a joint as crucial to locomotion as the hip joint of a cursorial dinosaur to be highly unlikely.

More recently, Farlow et al. (2000:645) wrote,

The antitrochanter repositioned from its primitive archosaurian location on the ischium, facing craniodorsally, to a more craniolateral orientation of the ischium and ilium in dinosaurs and their closest relatives. The antitrochanter then enlarged and re-oriented to face cranioventrally in birds.

Aside from the fact that this interpretation would require early theropods to hold their legs in a "grasshopper" mode, a pose that no one has yet suggested, this description attempts to establish a homology between two very different features. For example, the structure present on the pelvis of Coelophysis that Padian (1986) claimed to be an antitrochanter homologous to that of birds is intra-acetabular, and it is not an articular surface. Furthermore, Colbert (1989), in his detailed monograph on Coelophysis, makes no mention of an antitrochanter. It is also worth noting that Carrano (1998) concluded that there was little similarity in hindlimb locomotion between theropods and birds. That being the case, it is unlikely that a similar hip- joint construction would be found between the two groups. We suggest, as others have likewise done (e.g., Naples et al. 2002), that there is no common form or function for what is called an antitrochanter in dinosaurs and the avian antitrochanter.

It must be recognized that the avian antitrochanter did not simply appear and begin articulating with the proximal end of the femur. Rather, the lateral expansion of the femoral neck must have occurred in combination with the evolution of the linear antitrochanter as the femur began to abduct and move into a more horizontal position. The size of the femoral neck, as defined by Baumel and Witmer (1993), might therefore be taken as an indicator of the size of the antitrochanter in any avian taxon, especially when the FAAN of the femur can be delineated.

When the avian antitrochanter first appeared is still unknown. Because an antitrochanter does not occur in the oldest known birds, it must be assumed that it evolved subsequent to the establishment of the avian lineage. An antitrochanter appears in the Mesozoic Enantiornithes, and the presence of an antitrochanter in the late Cretaceous birds Hesperornis and Ichthyornis, and particularly the highly derived state of the antitrochanter in Hesperornis, argues for a fairly early appearance of this osteological feature within the avian lineage.

Summary. - We evaluated several linear and angular dimensions of the femur and pelvis of 77 species of birds with a wide variety of lifestyles and sizes to determine the role of the antitrochanter in locomotion. We found that femoral head diameter, femur length, and the area of the antitrochanter were highly correlated with log body mass. The angular measurements of the antitrochanter that described its spatial orientation in relation to the rest of the pelvis were not significantly correlated with log body mass, but they were consistent within morphofunctional groups. We interpret these results to mean that because the size of the antitrochanter correlates with the mass of a bird, it must play an important role in supporting the body of the bird. However, because the spatial orientation of antitrochanters is not consistent across all avian taxa, this must depend on leg function. The similarity of the spatial orientation of the antitrochanter among unrelated birds of similar locomotory habits, such as foot-propelled divers (loons, grebes, and hesperornithids), is consistent with this interpretation.

The antitrochanter is a uniquely avian osteological feature unrelated to the feature referred to as an antitrochanter in dinosaurs. It evolved 
as an additional acetabular articular facet for the femur as the avian femur assumed a more horizontal and abducted position. The change in the position of the femur was in response to the shifting forward of the center of mass in birds as they developed the large mass of anteriorly positioned pectoral muscles and lost the long, bony tail of their archosaurian ancestors. An antitrochanter does not occur in the oldest known birds, but it is present in Mesozoic enantiornithid and neornithid birds.

We propose that the antitrochanter developed in birds to assist in balance during bipedal locomotion by serving as a brace to prevent abduction of the hindlimb and to dissipate or resist stress that would otherwise be placed on the head of the femur. The linear, drum-intrough-like nature of the antitrochanter-femur articulation, as opposed to a more restricted cup-like articulation, serves to maximize the efficiency of the ginglymus between the neck of the femur and the antitrochanter. This is accomplished by helping to minimize rotational movement between the femur and pelvis, which helps to ensure that any long-axis, rotational movements of the femur are transferred to the pelvis without putting extreme stress on the head of the femur. Understanding the evolution of the avian antitrochanter will facilitate our understanding of the evolution of birds and their unique style of bipedal locomotion.

\section{ACKNOWLEDgments}

We thank D. Lauritzen, T. Sacco, and D. Sustaita for technical assistance; K. Garrett (LACM) and A. Alburo (UCLA) for curatorial assistance; and J. C. Torres Mura for his Spanish expertise. A. Milner and Z. Zhou kindly provided access to the London specimen of Archaeopteryx and the holotypic specimen of Caudipteryx dongi, respectively. Comments from $\mathrm{W}$. Bock and three anonymous reviewers helped to improve the manuscript.

\section{Literature Cited}

Altangarel, P., L. M. Chiappe, B. Rinchen, J. M. Clark, and M. A. Norell. 1994. Skeletal morphology of Mononykus olecranus (Theropoda: Avialae) from the Late Cretaceous of Mongolia. American Museum Novitates 3105:1-129.
Baumel, J. J., and L. Witmer. 1993. Osteologia. Pages 45-132 in Handbook of Avian Anatomy: Nomina Anatomica Avium, 2nd ed. (J. J. Baumel, Ed.). Publications of the Nuttall Ornithological Club, no. 23.

Bock, W. J., and W. DeW. Miller. 1959. The scansorial foot of the woodpeckers, with comments on the evolution of perching and climbing feet in birds. American Museum Novitates 1931:1-45.

Campbell, K. E., Jr., and L. Marcus. 1992. The relationship of hindlimb bone dimensions to body weight in birds. Pages 395-412 in Papers in Avian Paleontology Honoring Pierce Brodkorb (K. E. Campbell, Jr., Ed.). Natural History Museum of Los Angeles County, Science Series, no. 36.

Campbell, K. E., JR., and E. P. Tonni. 1983. Size and locomotion in teratorns (Aves: Teratornithidae). Auk 100:390-403.

Carrano, M. T. 1998. Locomotion in non-avian dinosaurs: Integrating data from hindlimb kinematics, in vivo strains, and bone morphology. Paleobiology 24:450-469.

Chinppe, L. M. 2001. Phylogenetic relationships among basal birds. Pages 125-139 in New Perspectives on the Origin and Early Evolution of Birds: Proceedings of the International Symposium in Honor of John H. Ostrom (J. Gauthier and L. F. Gall, Eds.). Yale University Press, New Haven, Connecticut.

Chiappe, L. M., M. A. Norell, and J. M. Clark. 2002. The Cretaceous, short-armed Alvaresauridae: Mononykus and its kin. Pages 87-120 in Mesozoic Birds: Above the Heads of Dinosaurs (L. M. Chiappe and L. M. Witmer, Eds.). University of California Press, Berkeley.

Chiappe, L. M., and C. A. Walker. 2002. Skeletal morphology and systematics of the Cretaceous Euenantiornithes (Ornithothoraces: Enantiornithes). Pages 240-267 in Mesozoic Birds: Above the Heads of Dinosaurs (L. M. Chiappe and L. M. Witmer, Eds.). University of California Press, Berkeley.

Colbert, E. H. 1989. The Triassic dinosaur Coelophysis. Museum of Northern Arizona Bulletin, no. 57.

Farlow, J. O., S. M. Gatesy, T. R. Holtz, JR., J. R. Hutchinson, AND J. M. Robinson. 2000. Theropod locomotion. American Zoologist 40:640-663. 
Feduccia, A. 1999. The Origin and Evolution of Birds, 2nd ed. Yale University Press, New Haven, Connecticut.

GateSY, S. M. 1994. Neuromuscular diversity in archosaur deep dorsal thigh muscles. Brain, Behavior and Evolution 43:1-14.

Gatesy, S. M. 1999. Guineafowl hind limb function. I: Cineradiographic analysis and speed effects. Journal of Morphology 240:115-125.

Gatesy, S. M., and K. P. Dial. 1993. Tail muscle activity patterns in walking and flying pigeons (Columba livia). Journal of Experimental Biology 176:55-76.

Heilmann, G. 1926. The Origin of Birds. Witherby, London.

Hertel, F. 1992. Morphological diversity of past and present New World vultures. Pages 413-418 in Papers in Avian Paleontology Honoring Pierce Brodkorb (K. E. Campbell, Jr., Ed.). Natural History Museum of Los Angeles County, Science Series, no. 36.

Hutchinson, J. R., and S. M. Gatesy. 2000. Adductors, abductors, and the evolution of archosaur locomotion. Paleobiology 26:734-751.

Jacobson, R. D., AND M. Hollyday. 1982. A behavioral and electromyographic study of walking in the chick. Journal of Neurophysiology 48:238-256.

Ji, Q., P. J. Currie, M. A. Norell, And S.-A. JI. 1998. Two feathered dinosaurs from northeastern China. Nature 393:753-761.

Johnston, R. M., AND A. Bekoff. 1996. Patterns of muscle activity during different behaviors in chicks: Implications for neural control. Journal of Comparative Physiology A 179:169-184.

Milne-Edwards, A. 1867-1868. Recherches anatomiques et paléontologiques pour servir à l'histoire des oiseaux fosiles de la France. Victor Masson and Sons, Paris. Text, vol. 1: 1-474; atlas, vol. 1: plates 1-96.

Mivart, St. G. 1874. On the axial skeleton of the ostrich (Struthio camelus). Transactions of the Zoological Society of London 8:385-451.

Naples, V. L., L. D. Martin, and J. Simmons. 2002. The pelvis in early birds and dinosaurs. Pages 203-210 in Proceedings of the 5th Symposium of the Society of Avian Paleontology and Evolution (Z. Zhou and F. Zhang, Eds.). Science Press, Beijing.

Owen, R. 1874a. On Dinornis (Part XVII): Containing a description of the sternum and pelvis, with an attempted restoration of Aptornis defossor, Ow. Transactions of the Zoological Society of London 8:119-126.

Owen, R. 1874b. On Dinornis (Part XVIII): Containing a description of the pelvis and bones of the leg of Dinornis gravis. Transactions of the Zoological Society of London 8:361-380.

Padian, K. 1986. On the type material of Coelophysis Cope (Saurischia: Theropoda) and a new specimen from the Petrified Forest of Arizona (Late Triassic: Chinle Formation). Pages 45-60 in The Beginning of the Age of Dinosaurs (K. Padian, Ed.). Cambridge University Press, London.

Paul, G. S. 2002. Dinosaurs of the Air: The Evolution and Loss of Flight in Dinosaurs and Birds. Johns Hopkins University Press, Baltimore, Maryland.

Pinshow, B., M. A. Fedak, and K. SchmidtNielsen. 1977. Terrestrial locomotion in penguins: It costs more to waddle. Science 195:592-594.

RAIKow, R. J. 1970. Evolution of diving adaptations in the Stifftail Ducks. University of California Publications in Zoology 94:1-52.

Romer, A. S. 1956. Osteology of the Reptiles. University of Chicago Press, Chicago, Illinois.

Storer, R. W. 1971. Adaptive radiation of birds. Pages 149-188 in Avian Biology, vol. 1 (D. S. Farner, J. R. King, and K. C. Parkes, Eds.). Academic Press, New York.

TARsitano, S. 1983. Stance and gait in theropod dinosaurs. Acta Palaeontologica Polonica 28: 251-264.

WALKer, A. D. 1977. Evolution of the pelvis in birds and dinosaurs. Pages 319-358 in Problems in Vertebrate Evolution (S. M, Andrews, R. S. Miles, and A. D. Walker, Eds.). Linnean Society Symposium Series, No. 4.

YounG, J. Z. 1950. The Life of Vertebrates. Oxford University Press, London.

Zhou, Z., AND L. Hou. 2002. The discovery and study of Mesozoic birds in China. Pages 160-183 in Mesozoic Birds: Above the Heads of Dinosaurs (L. M. Chiappe and L. M. Witmer, Eds.). University of California Press, Berkeley.

Associate Editor: H. F. James 
Appendix. Familes, family codes, and species used in the present study; $n=1$ for all species, except where indicated in parentheses after a species.

\begin{tabular}{|c|c|c|}
\hline Families & Code & Species \\
\hline Tinamidae & $\mathrm{T}$ & Rhynchotus rufescens, Nothura maculosa \\
\hline Rheidae & $\mathrm{J}$ & Rhea americana \\
\hline Spheniscidae & B & Eudyptula minor, Pygoscelis adeliae (2) \\
\hline Gaviidae & G & Gavia arctica, G. immer \\
\hline Podicipedidae & $\mathrm{O}$ & Aechmophorus occidentalis (2), Podilymbus podiceps, Podiceps grisegena \\
\hline Diomedeidae & $\mathrm{D}$ & $\begin{array}{l}\text { Thalassarche bulleri, T. cauta (2), T. chrysostoma, Diomedea exulans, } \\
\text { Phoebastria irrorata }\end{array}$ \\
\hline Procellariidae & $\mathrm{V}$ & $\begin{array}{l}\text { Fulmarus glacialis (2), Macronectes giganteus, Pterodroma externa, } \\
\text { P. longirostris, P. nigripennis, P. nivea, P. ultima, P. rostrata (2) }\end{array}$ \\
\hline Threskiornithidae & $\mathrm{K}$ & Phimosus infuscatus (2), Ajaia ajaja, Theristicus caudatus \\
\hline Ciconiidae & I & Mycteria americana \\
\hline Vulturidae & $\mathrm{X}$ & Gymnogyps californianus, Cathartes melambrotus (2), C. aura \\
\hline Anhimidae & $\mathrm{H}$ & Chauna torquata (2) \\
\hline Anatidae & $\mathrm{N}$ & $\begin{array}{l}\text { Anas acuta (2), A. cyanoptera, A. strepera, A. americana, A. clypeata, } \\
\text { A. platyrhynchos, Aythya americana, Bucephala albeola, Mergus } \\
\text { merganser, Calloneta leucophrys (2) }\end{array}$ \\
\hline Accipitridae & $\mathrm{C}$ & $\begin{array}{l}\text { Haliaeetus leucocephalus (2), Accipiter gentilis, A. cooperii (2), Buteo } \\
\text { jamaicensis (2) }\end{array}$ \\
\hline Falconidae & $\mathrm{F}$ & Falco sparverius (2), F. mexicanus, Milvago chimango, Caracara plancus \\
\hline $\begin{array}{l}\text { Phasianidae and } \\
\text { Odontophoridae }\end{array}$ & Q & Coturnix chinensis, Callipepla californica (2) \\
\hline Rallidae & $\mathrm{Z}$ & Eulabeornis ypecaha \\
\hline Aramidae & $\mathrm{Y}$ & Aramus guarana (2) \\
\hline Scolopacidae & $\mathrm{S}$ & Numenius tahitiensis, Tringa melanoleuca \\
\hline Laridae & $\mathrm{L}$ & Rissa tridactyla \\
\hline Alcidae & A & $\begin{array}{l}\text { Ptychoramphus aleuticus, Fratercula cirrhata, Aethia cristatella, } \\
\text { A. psittacula, Uria lomvia (2), Synthliboramphus antiquus }\end{array}$ \\
\hline Psittacidae & W & Amazona viridigenalis (2), Agapornis roseicollis \\
\hline Cuculidae & $\mathrm{U}$ & Geococcyx californianus (3) \\
\hline Apodidae & M & Streptoprocne rutila, S. zonaris, Chaetura cinereiventris \\
\hline Rhamphastidae & $\mathrm{R}$ & $\begin{array}{l}\text { Aulacorhynchus haematopygus, Glyptorhynchus spirurus, Pteroglossus } \\
\text { torquatus, Andigena laminirostris }\end{array}$ \\
\hline Picidae & $\mathrm{P}$ & Melanerpes formicivora, Colaptes auratus (3), Campephilus pollens (2) \\
\hline Dendrocolaptidae & E & Dendrocincla fuliginosa (2) \\
\hline
\end{tabular}

